\title{
Bir Adölesanda Nadir Bir Septik Şok Nedeni: Hamaktan Düşme Sonrası Oluşan Rektum Perforasyonu
}

\section{A Rare Case of Septic Shock in an Adolescent: Rectal Perforation Resulting from a Fall from a Hammock}

\author{
Hüseyin Kılınçaslan, İbrahim Aydoğdu, Orhan Kocaman*, Mustafa Hasbahçeci**, Mehmet \\ Bilgin***, Selçuk Alver**** \\ Bezmialem Vakıf Üniversitesi Tıp Fakültesi, Çocuk Cerrahisi Anabilim Dalı, istanbul, Türkiye \\ *Bezmialem Vakıf Üniversitesi Tıp Fakültesi, Gastroenteroloji Bilim Dalı, Istanbul, Türkiye \\ **Bezmialem Vakıf Üniversitesi Tıp Fakültesi, Genel Cerrahi Anabilim Dalı, Istanbul, Türkiye \\ ***Bezmialem Vakıf Üniversitesi Tıp Fakültesi, Radyoloji Anabilim Dalı, Istanbul, Türkiye \\ ****Bezmialem Vakıf Üniversitesi Tıp Fakültesi, Anesteziyoloji ve Reanimasyon Anabilim Dalı, Istanbul, Türkiye
}

\section{Özet}

Anorektal yaralanma çocuklarda nadir görülür. Bazen bu yaralanmalar peritoneal kontaminasyona yol açarak ciddi tablolara yol açabilir. Biz burada hamaktan düşme sonrası septik şok tablosunda başvuran ve rektum perforasyonu tanısı koyduğumuz 14 yaşındaki erkek hastayı sunduk. Hastaya sigmoid kolostomi yapıldı. Anorektal yaralanmalarda morbidite ve mortalitenin azaltılması için erken doğru tanı ile ek organ yaralanmalarının tespiti ve tedavisi gereklidir. Bu nedenle bizim olgumuzda olduğu gibi nadir ve atipik prezantasyonlar da akılda tutulmalıdır. (Haseki Tıp Bülteni 2014; 52: 133-6)

Anahtar Sözcükler: Rektum, perforasyon, hamak

\begin{abstract}
Anorectal injuries are rarely seen in children. These injuries may sometimes lead to peritoneal contamination and result in severe clinical manifestations. Herein, we present a 14-yearold male patient who presented with symptoms of septic shock and was diagnosed with rectal perforation occurring after a fall from a hammock. The patient underwent sigmoid colostomy. In order to decrease the morbidity and mortality from anorectal traumas, an early and accurate diagnosis as well as detection and treatment of additional organ injuries are required. Therefore, atypical presentations should be born in mind. (The Medical Bulletin of Haseki 2014; 52: 133-6)
\end{abstract}

Key Words: Rectum, perforation, hammock

\section{Giriş}

Anorektal yaralanmalar çocuklarda oldukça nadirdir. Nedenleri arasında cinsel istismar, anüsten yabancı cisim sokulması, ateşli silah yaralanmaları ve travma yer alır. Gelişmiş ülkelerde ilk sırada cinsel istismar gelirken, ülkemizde ilk sırada künt travma ve yüksekten düşme gelmektedir. Bu farklılığın, ülkemizde konu ile ilgili bilginin az olması, korku nedeniyle minör yaralanmalarda çoğu kez sağlık kuruluşlarına başvurulmaması, başvurulduğunda ise konunun sağlık kuruluşunda yeterli irdelenmemesi gibi nedenlerden ileri geldiği düşünülmektedir. Ayrıca sosyokültürel farklılık da diğer bir faktördür. Anorekral yaralanmalarda standart yaklaşım primer onarımdır.
Fakat peritoneal kontaminasyon olan ve/veya tanının sekiz saatten fazla geciktiği vakalarda kolostomi açılması önerilmektedir $(1,2)$.

\section{Olgu}

Karın ağrısı ve safralı kusma şikayetleri ile acil kliniğimize başvuran on dört yaşındaki erkek hasta tarafımıza apandisit ön tanısı ile konsülte edildi. Hastanın acil serviste yapılan batın ultrasonografisi perfore apandisit ile uyumluydu. Hikayesinde üç yıldır kabızlığı olduğu, beş gün önce hamaktan sivri bir cisim (kesilmiş ağaç kökü) üzerine düştüğü, bu sırada üzerindeki giysinin anüse denk gelen kısmının yırtıldığı, anüse bir cismin battığını hissettiği, 
hemen sonrasında anal bölge ağrısının, düşmeden bir gün sonra karın ağrısı ve kusmasının başladığı ifadesi mevcuttu. Fizik muayenesinde tüm batında hassasiyet, defans ve rebaund tespit edildi. Perine muayenesinde anüs çevresinde ekimotik alanları, litotomi pozisyonunda saat on iki hizasında derin bir anal fissürü vardı, rektal tuşede özellik yoktu. Anal tonus normal olarak saptandı. Ateşi $\left(39,2^{\circ}\right)$ ve taşikardisi $(160 / \mathrm{dk})$ mevcuttu. Arteriyel kan basıncı 60/40 mmHg idi. Üç gündür defekasyonu yoktu. Oskültasyonda barsak sesleri alınamadı. Laboratuvar değerleri şu parametreler hariç normaldi: Lökosit 29,800/ $\mathrm{mm}^{3}$, C-reaktif protein 21,4 mg/dl, sodyum $130 \mathrm{nmol} / \mathrm{l}$, klor $97 \mathrm{mmol} / \mathrm{l}$. Ayakta batın grafisinde diafragma altında serbest hava izlendi (Resim 1). Hastada intestinal perforasyon düşünüldü. Batın içi ek patolojilerin tespiti amacıyla bilgisayarlı batın tomografisi çekildi. Rektum ön duvarda perfore alan tespit edildi (Resim 2). Ayrıca diafragma altında serbest hava ve karaciğer kapsülünde peritonite bağlı olarak kontrast tutulumu görüldü (Resim 3). Hasta operasyona alındı ve önce rektoskopi yapıldı. Linea dentataya $4 \mathrm{~cm}$ mesafede, rektum ön duvarında $3 \mathrm{~cm}$ 'lik perforasyon olduğu görüldü. Daha sonra göbek üstü-altı orta hat kesisi ile laparotomiye geçildi. Tüm batında fekaloid içerikli materyal olduğu görüldü ve ileri derecede peritonit bulguları tespit edildi. Rektumdaki perforasyon

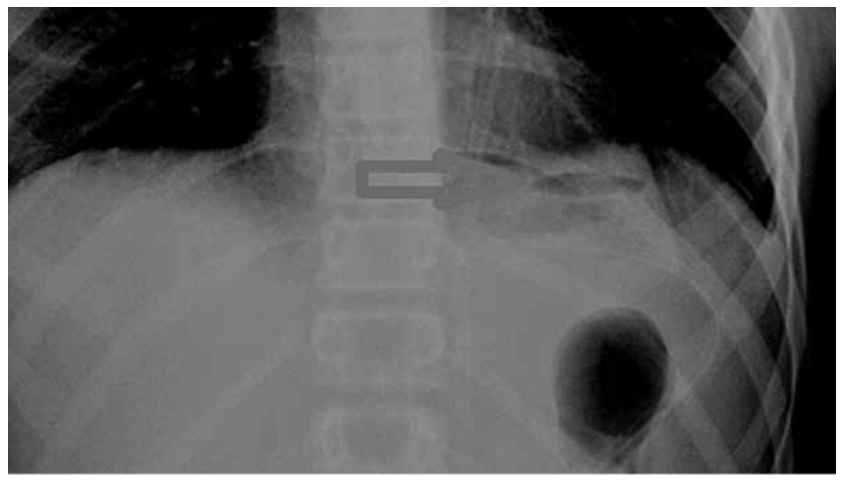

Resim 1. Ayakta direkt batın grafisinde diafragma altı serbest hava görülmektedir

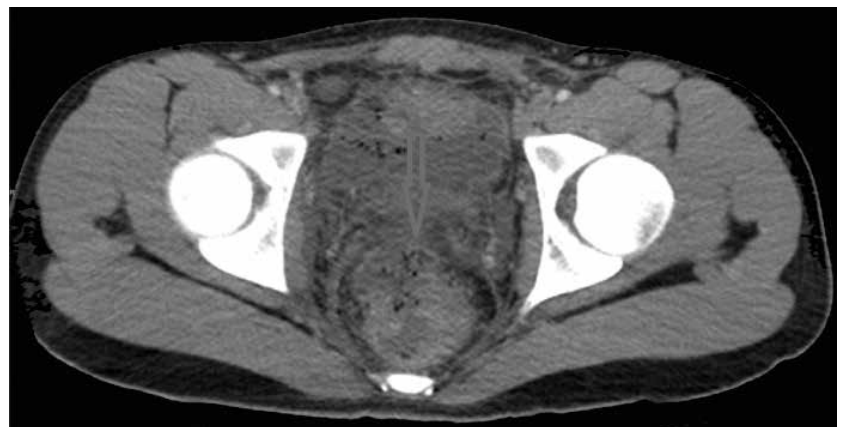

Resim 2. Bilgisayarlı batın tomografisinde rektum ön duvarında ki düzensizlik ve perfore alan görülmektedir alanı görüldü (Resim 4) ve burası primer olarak onarıldıktan sonra pelvise penroz dren yerleştirilerek sigmoid kolostomi yapıldı. Postop 3. ayda yapılan sigmoidoskopide perfore alanın kapandığı teyit edildi (Resim 5) ve sigmoid kolostomi kapatıldı. Hastanın takiplerinde sorunu olmadı.

\section{Tartışma}

Anorektal yaralanmalar sıklıkla cinsel istismar, ateşli silah yaralanmaları, travma ve anüsten yabancı cisim uygulamalarına bağlı olarak gelişmektedir (1-7). Literatürde daha az görülen durumlar da bildirilmiştir. Bunlar hemoroid operasyonuna bağı iatrojenik (8), su kayağı sonucu rektum içinde aşırı sıvı birikimine ve yüksek basınç nedeniyle oluşan (9), trafik kazası sonrası divertikül perforasyonuna ikincil (10) ve fekal impaksiyona bağlı (11) rektum perforasyonlarıdır.

Çocuklarda intrapelvik organlar daha alçak yerleşimlidir; rektum, vajen, mesane gibi intraabdominal

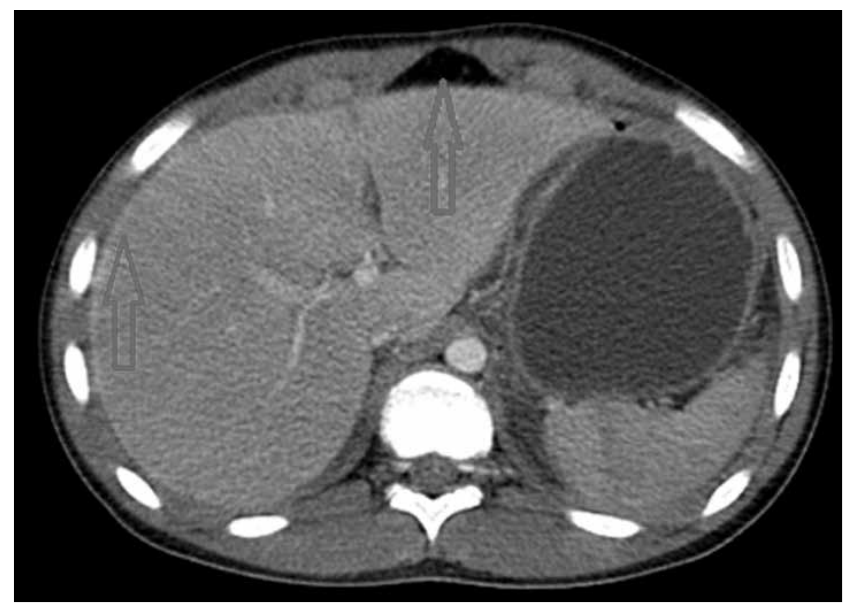

Resim 3. Bilgisayarlı batın tomografisinde diafragma altı serbest hava ve karaciğer kapsülünde peritonite bağlı kontrast tutulumu görülmektedir

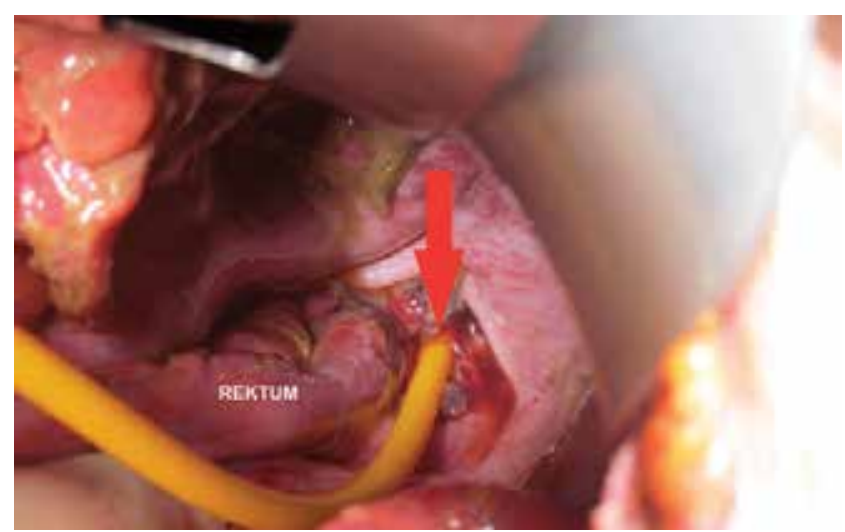

Resim 4. Intraoperatif olarak perforasyon alanından ilerletilen foley sondanın distale doğru geçtiği görülmektedir 


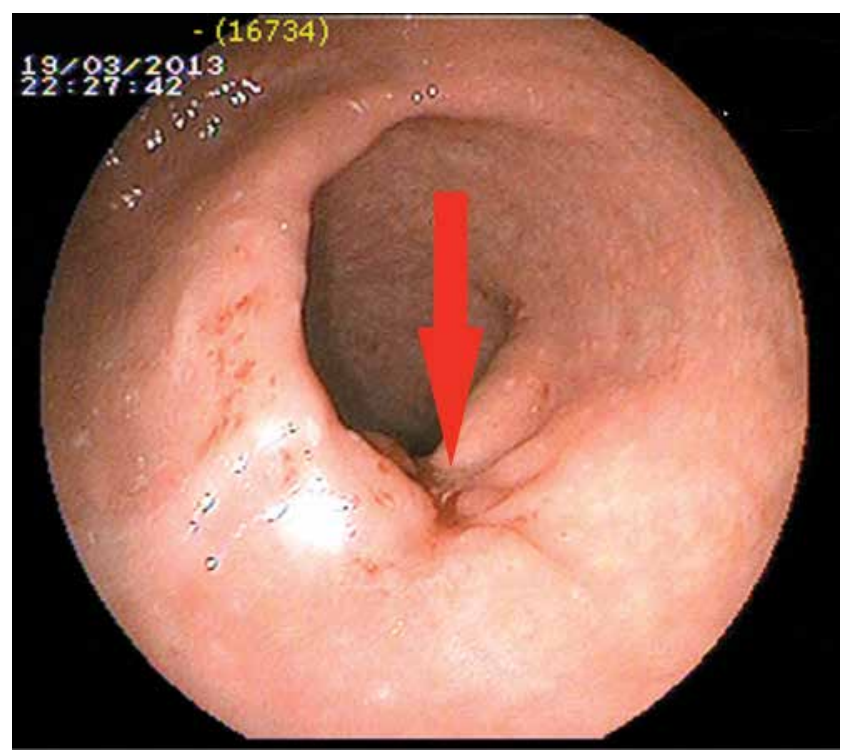

Resim 5. Postop 3. ayda yapılan kolonoskopide rektumdaki perfore alanın iyileştiği ve darlık oluşturmadığı görülmektedir

organların yaralanmaya eşlik etme ve peritoneal kontaminasyon olasılığı daha fazladır. Anorektal yaralanmalar ekstra veya intraperitoneal yaralanmalar şeklinde sınıflandırımaktadır $(4,5,12)$. Erken dönemde başvuran olgularda karın muayene bulgularının normal olması batın içi yaralanmayı ekarte ettirmemeli ve atipik prezantasyonlar mutlaka akılda tutulmalıdır. Önemli noktalardan biri de eşlik edebilecek diğer organ yaralanmaları sonucu gelişebilecek sepsis ve yaralanan organa bağı ortaya çıkabilecek komplikasyonlar nedeni ile ileri tanısal çalışmaların yapılması gerektiğidir.

Olgumuz acil serviste ilk muayene ve radyolojik bulgular ışığında perfore apandisit ön tanısı ile tarafımıza konsülte edilmiştir. Fakat fizik muayene ve özellikle de dikkatli bir anamnez sonucunda yanlış tanı dışlanmış ve doğru tanıya ulaşılmıştır.

Rektum yaralanmalarında mortalite ve morbiditeyi azaltmak için yaygın ve nadir tüm prezantasyonlarının bilinmesi önemlidir. Cinsel istismar, rektum yaralanmalarının önemli nedenlerinden biridir. Özellikle erkek çocuklarda tanısı zor konulan bir durumdur. Fizik muayene bulguları anal deri katlantısı, lokalize venöz konjesyon varlığı ve eksternal sfinkter dilatasyonudur (13). Cinsel istismara ek olarak otoerotik uygulamalar da rektum yaralanmalarının önemli nedenlerindendir. Otoerotik uygulamalar çocuk yaş grubunda nadir olmasına rağmen bu duruma mental retardasyonu olanlarda ve adölesanlarda rastlanabilmektedir. Tanı koymak zordur ve inkar mekanizması geçerlidir $(14,15)$. Intramural hematom ve sterkoral ülserlere bağlı gelişen rektum perforasyonları ise nadir durumlara örnektir. Gastrointestinal intramural hematomlar nadirdirler ve özofagustan rektuma kadar herhangi bir alanda görülebilir. Sıklıkla travmaya ikincil gelişirler. Travma dışı nedenler ise sıklıkla hematolojik hastalıklar sırasında alınan antikoagülan tedaviye bağlıdır. Rektal hematom sonrası ıkınmaya bağlı abdominal basınç artar ve rektum kontrakte olur. Kontrakte rektumun intramural basınc artar ve vasküler kompliyansın düşmesi ile perforasyona kadar giden olaylar zinciri başlar $(6,7)$. Kabızlığa ve fekal impaksiyona bağlı rektum perforasyonu ise sterkoral ülser gelişiminden kaynaklanır. Fekal impaksiyon rektumda kitle etkisi yapar ve artan basınç iskemi, nekroz ve eroziv ülserle sonuçlanır (12). Olgumuz, anamnez ile ameliyat bulguları arasında açık bir ilişki ortaya konulmasına rağmen yine de cinsel istismar ve otoerotik uygulama açısından Çocuk Psikiyatrisi tarafından araştırımış ve herhangi bir bulguya saptanmamıştır. Operasyon öncesi anüsten alınan sürüntüde sperme rastlanmamıştır.

Anorektal yaralanmalarda tedavide ilk aşama geniş spektrumlu antibiyotik başlanmasıdır. Ekstraperitoneal yaralanmalar perineal ise yara debridmanı ve onarım yapılırken; transanal ise cerrahi girişim gerektirmeyebilir. Bu olgularda geniş ve ciddi yaralanmalarda nadiren kolostomi gerekebilmektedir. Intraperitoneal yaralanmalarda ise gerek perineal gerekse transanal olsun kolostomi önerilmektedir $(3,4)$. Özellikle sekiz saatten sonra başvuran intraperitoneal rektum yaralanmalarında kolostomi yapılması yüksek bir öneme sahiptir. Olgumuzda geniş spektrumlu antibiyotik tedavisi başlandıktan ve hemodinami düzeltildikten sonra laparotomi yapılarak perforasyon alanı primer olarak onarılmıştır. Gecikmiş vaka olması ve yaygın peritoniti olması dolayısı ile kolostomi açılmışıı. Kolostomi, postop 3. ayda kapatılmıştır. Klinik takipler 9. aya kadar sürdürülmüş ve soruna rastlanmamıştır.

Anorektal yaralanmalarda erken ve doğru tanı morbidite ve mortalitenin azaltılması için gereklidir. Bu amaçla nadir görülen prezantasyonların bilinmesi ve peritoneal kontaminasyon varlığında kolostomiden kaçınılmaması gerektiğini düşünüyoruz.

\section{Kaynaklar}

1. Oztürk H, Onen A, Dokucu Al, Otçu S, Yağmur Y, Yucesan S. Management of anorectal injuries in children: an eighteenyear experience. Eur J Pediatr Surg 2003;13:249-55.

2. Bonnard A, Zamakhshary M, Wales PW. Outcomes and management of rectal injuries in children. Pediatr Surg Int 2007;23:1071-6.

3. Crass RA, Tranbaugh RF, Kudsk KA, Trunkey DD. Colorectal foreign bodies and perforation. Am J Surg 1981;142:85-8.

4. Grisoni ER, Hahn E, Marsh E, Volsko T, Dudgeon D. Pediatric perineal impalement injuries. J Pediatr Surg 2000;35:702-4.

5. Kim S, Linden B, Cendron M, Puder M. Pediatric anorectal impalement with bladder rupture: case report and review of the literature. J Pediatr Surg 2006;41:1-3. 
6. Li ZL, Wang ZJ, Han JG. Spontaneous perforation of an intramural rectal hematoma: report of a case. World J Gastroenterol 2012;18:2438-40.

7. TerKonda SP, Nichols FC 3rd, Sarr MG. Spontaneous perforating hematoma of the rectum. Report of a case. Dis Colon Rectum 1992;35:270-2.

8. González-Contreras QH, Jiménez-González A, Vega-Batista $R$, González-Longoria G, Salinas-Aragón LE. Rectal perforation as a result of stapled hemorrhoidectomy. Cir Cir 2012;80:287-90.

9. Gill RS, Mangat H, Al-Adra DP, Evans M. Hydrostatic rectosigmoid perforation: a rare personal watercraft injury. J Pediatr Surg 2011;46:402-4.

10. Yaşar NF, Kebapçı M, Ihtiyar E. Pneumomediastinum and subcutaneous emphysema caused by sigmoid diverticulum perforation secondary to blunt abdominal trauma: report of a case. Ulus Travma Acil Cerrahi Derg 2011;17:93-5.
11. Arana-Arri E, Cortés H, Cabriada V, Lekerika N, García-Verdugo A, Shengelia-Shapiro L. Giant faecaloma causing perforation of the rectum presented as a subcutaneous emphysema, pneumoperitoneum and pneumomediastinum: a case report. Eur J Emerg Med 2007;14:351-3.

12. Oakenful C, Lambrianides AL. Stercoral perforation of the rectum. Emerg Med Australas 2011;23:224-7.

13. Kadish HA, Schunk JE, Britton H. Pediatric male rectal and genital trauma:accidental and nonaccidental injuries. Pediatr Emerg Care 1998;14:95-8.

14. Yacobi Y, Tsivian A, Sidi AA. Emergent and surgical interventions for injuries associated with eroticism: a review. J Trauma 2007;62:1522-30.

15. El-Ashaal YI, Al-Olama AK, Abu-Zidan FM. Trans-anal rectal injuries. Singapore Med J 2008;49:54-6. 